\title{
Integrated Design and Evaluation of Logistic Networks: Oriented Placement of the Order Penetration Point
}

\author{
Katja Klingebiel \\ Fraunhofer Institute for Material Flow and Logistics, Dortmund, Germany \\ Bernd Hellingrath \\ Westfälische Wilhelms-Universität, Münster, Germany \\ Silvio Roberto Ignacio Pires \\ Methodist University of Piracicaba (UNIMEP), Piracicaba, SP, Brazil

\section{Luiz Felipe Scavarda} \\ Pontifícia Universidade Católica do Rio de Janeiro (PUC-Rio), Rio de Janeiro, RJ, Brazil
}

\begin{abstract}
The placement of the Order Penetration Point (OPP) is a key decision in automotive supply chains since the product will be differentiated according to the customers' requirements only after the OPP. From a marketing perspective variety proliferation is encouraged. Yet, competition has shifted from individual firms to global supply chains and under given market uncertainty the significance of supply chain flexibility is increasing. Upstream however, the expansion of outsourcing, supplier rationalization and lean production practices has yielded substantial progress in terms of supply chain efficiency. In order to economically operate the supply chain, the positioning of order penetration points is vital to inflict as much downstream process and product flexibility to be amenable to changing market demand and to guarantee as much upstream stability to allow for accurate and risk-controlled planning of cost-efficient supply chain processes. This paper identifies and analyses the main factors related to OPP problems and presents a method for OPP positioning under a supply chain perspective, integrating the influence of product diversity and supply chain flexibility over a complete product life-cycle systematically.
\end{abstract}

Keywords: Supply chain management, Order penetration point, Automotive industry, Supply chain flexibility, Product diversity.

\section{Introduction}

The Order Penetration Point (OPP) is not a new subject as it has already been a topic of interest since the 1980's (Bowersox and Morash, 1989), when Sharman defined it as the point at which a product becomes earmarked for a particular customer and where product specifications get frozen (Sharman, 1984). It is typically considered the last point at which inventory is held. However, the positioning of the OPP has been successively becoming a topic of strategic interest, especially within global 
markets, increasing global competition and shorter product life cycles (Olhager, 2003). This interest and importance is even more accentuated in industries that embrace global organizations with high product diversity resulting in the need for intra/interorganizational flexibility (Holweg and Pil, 2004; Pires and Diaz, 2007). This holds especially true for the automotive industry which is consequently in focused here. The choice of the automotive industry as the object of study was reinforced by the fact that this industry has been at the forefront of many managerial and industrial developments throughout the world (Thun and Hoenig, 2011).

Within this context, the main goal of this paper is to analyze the implications of OPPs within the auto industry supply chain focusing on product diversity management and supply chain flexibility. The paper also offers a methodology for the positioning of OPPs within automotive supply chains.

Therefore, the paper first introduces the concepts of product diversity, supply chain flexibility and OPP decision. The discussion and inclusion of the auto industry in the debate is also offered along these first sections. Next, the paper presents the methodology for OPP positioning based on the literature and on the authors background aided by in locus visits and non structured interviews with key managers of the German and Brazilian automotive industry. Finally, concluding remarks and recommendations for future research are offered.

\section{Product Diversity}

Product diversity, also called product variety, can be defined as the number of different versions of a product offered by a firm at a single point in time (Randall and Ulrich, 2001), as the number of different products offered to customers (Pine, 1993), and the number of variants within a specific product group (Vaagen and Wallace, 2008). It can be expressed by many types like colours, flavours, sizes, features, countries, geometry, among others. The current trend of proliferation of product diversity has been increasing the attention given by academics and practitioners (Bayus and Putsus, 1999; Syam et al., 2005; Wu et al., 2007). Product diversity has been analyzed from different perspectives including operations, marketing, economics and environmental (Lancaster, 1990; Kotler et al., 1995; Tang and Yam, 1996; Shile, 2009), with a big impact on business strategies (Da Silveira, 1998).

Mitigation strategies are used to allow for a more cost-efficient provision of product diversity and can broadly be grouped into three categories: changes in product architecture, in particular the use of modular and platform strategies and component standardization, flexibility in manufacturing operations, such as quick machine changeovers and multi-skilling of the workforce, and postponement of product configuration decisions beyond the final assembly of products into the distribution system, also referred to as late configuration (Scavarda et al., 2010). Within postponement diversity can be made available ex factory or late-configured in the distribution system, for instance, in the car dealers for the auto industry.

\section{Auto Industry in Industrialized and Emerging Countries}

Holweg and Pil (2004) and Midler (2005) analyzed the evolution of product diversity in the European auto industry. Scavarda et al. (2009) and Schaffer (2010) 
presented and analyzed the significant differences between this product diversity and the one offered in emerging countries. The total number of variants for vehicle models offered in industrialized countries exceeds by far the one offered in emerging countries. For example, the Ford Focus sedan model is offered in Germany with almost 10 billion times the one offered in China or in Brazil. These differences in the number of variants offered are found in all analyzed auto segments worldwide (Scavarda et al., 2009).

Investigating the reasons for the variety restrictions in Latin America, when compared to Europe, Scavarda et al. highlight the notion of a cost-revenue trade-off function of product variety, by which certain specifications were only offered when the projected incremental revenues exceeded projected incremental costs by the required profitability margin (Scavarda et al., 2010). Their work also took to a closer examination of the costs involved along the supply chain (Lechner et al., 2011).

The empirical multi-tier studies that have been conducted by the authors in the South American and in European automotive industry reveal that the key difference between the Latin American and the European markets was the importance of the retail price to end customers. Customers in Latin America were considered more price-conscious and seldom demanded expensive options, such as satellite navigation systems. According to Scavarda et al., (2010), the general restriction of variety in emerging countries, based on an examination of the main costs involved along the Supply Chain, are:

- Research and Development (R\&D) costs: as many specifications are developed in parent companies one could suggest low local R\&D costs as there is less local effort, however, specifications offered in a new regions have to go through a certification process (quality standards and legal requirements). Local adaptations are required to avoid malfunctioning of parts (different climate and road conditions) results in further testing;

- Supply costs: locating a supplier, high overhead ration if the overall volume is low; integrating the new parts into its existing logistics network (Greenfield area); low demand for some components (e.g. less than one component required per week); avoid imports (overseas transportation, product documentation for customers clearing, more complexity of coordinating the supply chain;

- Manufacturing costs: new specification can potentially increase investment for equipment (e.g. body shop for offering an additional body style for example); employee training would add to the cost (e.g. train how to assemble a door with side curtain airbags - more difficult with lower skill levels); increase complexity in the manufacturing process (more parts to be handled during final assembly);

- Sales and distribution costs: dealers need to be trained, and product documentation and marketing material to be created.

Scavarda et al. (2010) also highlight that only the ex factory product variety in Latin America neglects a key dimension in the overall product variety management process: late configuration, which the vehicle distribution system in general in Latin America relies on extensively. Stäblein et al. (2011) propose and validate product diversity measures in the auto industry based on actual customer orders, and empirically demonstrate how these measures can be used to assess the impact of late configuration and option bundling strategies, and find that these are generally valid, but that their 
applicability is contingent upon the respective variety distribution profile offered (Stäblein et al., 2011).

Recapitulating though product diversity is handled differently in industrialized and emerging countries, it is driving the supply chain configuration with significant implications on costs and service levels.

\section{Supply Chain Flexibility}

Flexibility has been researched for decades with a considerable amount of knowledge disclosed in the area (Slack, 1983). Accordingly, the vast majority of published contributions are related to studies on flexibility within companies, i.e., has an internal scope. It is usually defined as the ability to react or change to environmental uncertainly with minimum penalty in terms of time, effort, cost or performance (Upton, 1994).

Alongside, over the past two decades competition has shifted from individual firms to whole supply chains perspective (Lambert and Cooper, 2000; Christopher, 2005). In this sense, some of the key debates in the operations management domain have extended their scope beyond the single company to include supply chain partners and their interactions. Consequently, supply chain flexibility or even adaptability has emerged as a key subject of supply chain management. Likewise, taking the original definition of Upton (Upton, 1994), it should be defined as the supply chain ability to react or change to environmental uncertainly with minimum penalty in terms of time, effort, cost or performance. Supply chain flexibility is also defined to encompass those flexibility dimensions that directly impact a firm's customers and are the shared responsibility of two or more functions along the supply chain, whether internal or external to the firm (Sanchez and Perez, 2005).

Tachizawa and Giménez (2007) use the concept of drivers and sources of flexibility defined, respectively, as "a factor that determinates the need for flexibility" and as "specific actions to generate flexibility". In this sense, usually some flexibility drivers are related to demand volatility and fluctuation in production schedules. Furthermore, flexibility drivers can be generated internally within the focal company or externally within suppliers or customers. Hence, low material commonality should be an example of internal drivers, while demand volatility, seasonality and cyclicality gives an example of external drivers. These authors also highlight that flexibility drivers can be related to three main types of uncertainly: volume, mix and delivery. Accordingly demand volatility and incomplete supplies are examples of volume uncertainly. Changes in the master production schedule already sent to supplier may be related to volume, mix and delivery uncertainly. In turn, flexibility sources should be related to the type of sourcing strategy, e.g. long-term partnerships or short-term bids, supplier base responsiveness, inventory buffers, joint product development, and more.

When analyzing the drivers and sources of supply (inbound) flexibility within four industrial sectors in Spain (automotive, apparel, electronic and electrical equipment), Tachizawa and Giménez (2007) observed within the studied companies in Spain "a balance between internal and external drivers" and "an important exception within the automotive sector, in which internal drivers seems to be more important than external ones. 
Aggravating the need for supply chain flexibility, it should be remembered that production in the early years was simple, with single flow of products moving from raw material suppliers, to manufacturers and then to markets.

It is generally known that the expansion of outsourcing, supplier rationalization and lean production practices yielded significant progress in terms of supply chain efficiency. However, this trend also involved a considerable increase in supply chain risks, particularly those related to supply interruptions due to external uncontrollable factors, e.g. the recent earthquake in Japan.

More recently the extended supply chain from a globalization perspective has inevitably increased the importance of what has been called Supply Chain Risk Management (SCRM) (Tang and Nurmaya, 2010). In this context authors such as Barry (2004) and Wu (2006) have studied SCRM in uncertain global environments.

Accordingly, for manufacturing companies with global operations this scenario represents a larger complexity in conducting its supply chain operations, with consequent increase in costs. Therefore, supply chain risk management seeks mainly to reduce the supply chain's dependency of identified risks, that is, be more effective in mitigating the risks. Likewise, this means to reduce mainly disruptions and recovery time. In this sense, SCRM depends highly on supply chain flexibility.

\section{OPP Decisions in Global Supply Chains}

Every acting enterprise in a supply chain is driven by three obstacles: first to inflict as much downstream process and product flexibility to be amenable to changing market demand; second to guarantee as much upstream stability to allow for accurate planning of cost-efficient supply chain processes, third to manage risks with suitable flexibility measures. Whereas the first is a more sales driven objective, the last two are production and supply chain driven objectives. Accordingly it is a significant decision in strategic supply chain design where to divide a supply chain into upstream risk-controlled, but stable processes, which rely on order speculation, and downstream market-flexible processes, which rely on order commitment. This problem is generally known as positioning of the Order Penetration Point (OPP) (Sharman, 1984; Christopher and Towill, 2000).

The OPP is defined as a point in a supply chain from which on a product is assigned to a customer order (Olhager, 2003). Also regarded as the point at which real demand penetrates upstream in a supply chain and termed as de-coupling point, it should dictate the form in which inventory is held (Christopher and Towill, 2000). Downstream of this order penetration point, customer orders drive the systems that control material flows, upstream forecasts and plans (Sharman, 1984). When the OPP is located closer to the end of the line, customer demand is fulfilled from inventory. Inventory replenishment and production planning are based on forecasts of demand during lead time. The safety stocks are high as they are proportional to uncertainty about customer demand and production lead times. When the OPP is moved to the beginning of the line, production is on order. Inventory of finished goods is low (or nonexistent) but customer service is critical (Andries and Gelders, 1995). Thus, the OPP marks the transition between two production strategies that are typically practiced in contemporary production and logistics networks (Winkler, 2010). 
Literature already offers many factors that affect the positioning of the OPP (see for instance Sharman, 1984; Bowersox and Morash, 1989; Christoper and Towill, 2000; Winkler, 2010). The most important factors affecting the positioning of the OPP relate to four categories:

- Market-related factors (e.g. service level requirements, demand volatility, demand uncertainty, product volume, product range and product customization requirements, order size and frequency);

- Product-related factors (e.g. modularisation, customization opportunities);

- Supply chain and material flow characteristics (e.g. production lead time, number of planning points in a manufacturing process, flexibility of the production process, the position of the bottleneck of the production, etc).

The market characteristics affect product characteristics. The product range and customization opportunities interact with market expectations and result in a delivery lead time that customers require with respect to the product offering. These factors are input to the production function. The product structure can be interpreted in terms of lead time with respect to the operations that need to be performed at each level. The relationship between production and delivery lead times is a major determinant of the OPP position (Olhager, 2003).

As already discussed, in emerging countries OPPs are positioned downstream, near the customer. E.g. in Brazil many vehicles are late configured at dealers, whereas in Europe customization is done at the OEM plant level. From a first view it seems that supply chains in countries like Brazil offer more flexibility embracing the postponement strategy, but one should consider that just peripheral varieties (e.g. seat cover, radios and alarms) may be fitted in the vehicles at dealers. All fundamental varieties are fitted at the plant level (e.g. body type, paint and trim and engines).

\section{Positioning of Order Penetration Points in the Global Auto Industry Supply Chain}

Consequently, the OPP is gaining relevance in strategic logistics planning for global automotive networks (Olhager, 2003) as shifting the OPP up- or downstream in the supply chain affects service levels and costs. Many authors already dedicated their work to the problem where to position the OPP in order to maximize efficiency and flexibility (Yang et al., 2004). Nevertheless this problem is generally underestimated due to several reasons. The two most prominent are that, first, within a supply chain there is not only one order penetration point; and second, order penetration points are typically smeared over more than one process in the supply chain:

The automotive supply chain is characterized by trilateral relationships between OEM, dealer (also importer or sales organization) and customer which allows for a wide range of order inflow (Klingebiel, 2009). Depending on the OPP position, several product delivery strategies can be defined (Bozarth and Chapman, 1996; Olhager, 2003; Klingebiel, 2009):

- Make-to-stock with an OPP before shipment;

- Assemble-to-order with an OPP between procurement and final assembly; 
- Make-to-order leading to an OPP after the product design and;

- Engineer-to-order implicating an OPP before the design.

Yet, concepts like Amend-To-Order (ATO) and Locate-To-Order (LTO) bridge between the pure BTO concept of direct ordering and the concept of Build-toStock (BTS) (Figure 1). And all of these concepts are often well established in one OEM's production system. The according order pipeline comprises planned orders, dealer-assigned orders, customer-assigned orders and dealer-and-customer-assigned orders (Simchi-Levi et al., 2007; Gunasekaran and Ngai, 2005). Thus, at least two different, more or less strongly correlated order types penetrate the automotive supply chain. And even worse, these orders enter the supply chain somewhere between a very early stage of planning, e.g. month in advance of vehicle production, and a very late stage of material flow, e.g. while or after being produced, shipped or handed over to a third party.

Further upstream, processes in the supply chain can be divided into a series of order management cycles, each occurring at the interface between two successive supply chain stages (Chopra and Meindl, 2007). Each of these cycles is driven by either order speculations, i.e. consisting of push processes, or order commitment, i.e. consisting of pull processes. Each cycle triggers demand in upstream cycles. If the interface between two cycles separates downstream pull processes from upstream push processes one easily recognize an order penetration point as defined. Yet, push processes also initiate demand, i.e. orders, in upstream following cycles. These upstream cycles might be driven by corresponding order commitment and another OPP might follow further upstream. A common example in the automotive supply chain for this specific setting is the just-in-sequence delivery of engines (Toth et al., 2008). The BTO-production of engines is triggered by production orders from the vehicle plant, which themselves might be built-to-stock orders.

And additionally, it is a quite common concept to work with batch-sizes in order driven processes. A prominent example is the body paint shop at BMW: no body-in-white is painted without at least one according order. Yet, this process is driven purely by order order volume. Certain flexibility is inflicted in the order management

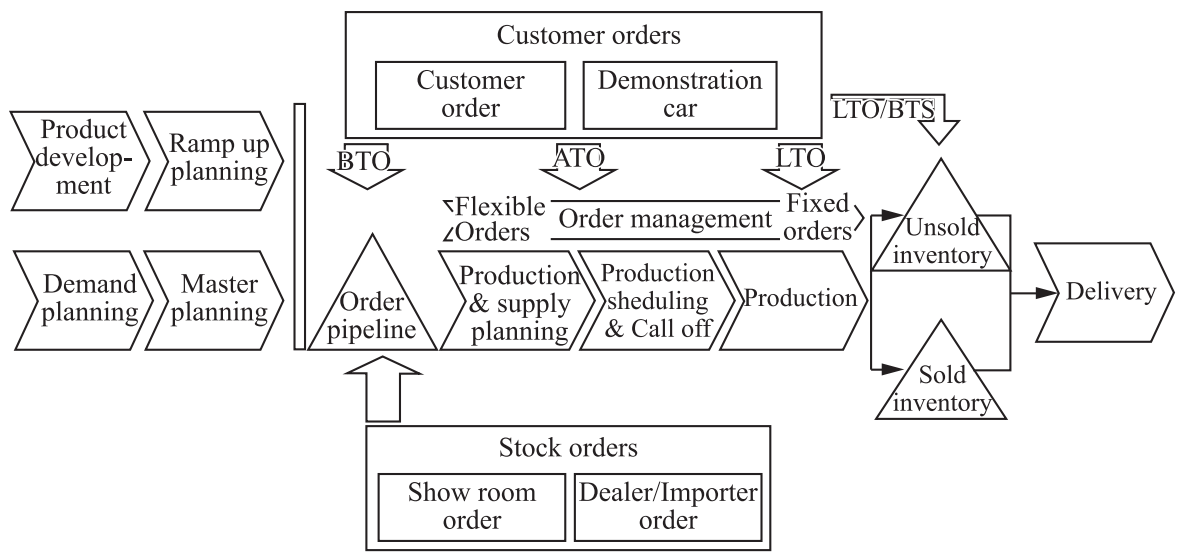

Figure 1. Automotive planning framework (Klingebiel, 2009). 
process by buffering painted bodies before assigning orders to the specific painted body just before final assembly. This specific concept of order-anonymous preproduction is one of the means to smear the Order Penetration Point over a series of processes. Other examples are specific forms of postponement as seen in late configuration or late customization, which can occur along the entire supply chain, from sourcing to final distribution (van Hoek, 2001).

Concluding, when deciding about the position of an order penetration point the possibilities, which all of these described concepts bear, have to be taken into account. Thus it is not sufficient to assess the isolated order penetration point, but it is evidently necessary to involve design options, influencing factors as well as assessment criteria for involved upstream and downstream processes. A holistic, integrated and exhaustive assessment is necessary as only this view on the supply chain allows for assessment of overall profitability (Simchi-Levi et al., 2007). Within this context, a methodology for the placement of OPPs in global automotive supply chains is proposed which integrates the influence of product diversity and resource flexibility under a supply chain perspective.

\section{Methodology for OPP Positioning}

The optimal placement of the OPP is influenced by market strategy, product strategy and supply chain capability. Literature already identified a multitude of influencing factors, e.g. inventory costs, production and delivery lead times, demand uncertainty, obsolescence risks of products and parts. Within an extensive literature analysis influencing factors and respective frameworks have been analysed thoroughly against the background of OPP positioning being an instrument of supply chain design.

Many approaches have been already dedicated to the problem of where to position the OPP in order to balance efficiency and responsiveness within a supply chain. A thorough analysis identified two general approaches (Klingebiel et al., 2011; Winkler 2010): Qualitative approaches give rec-ommendations for OPP positions based on a selection of influencing factors and their respective qualitative characteristics. Quantitative approaches derive a specific position based on an analytical model of the supply chain. None of these approaches includes all indentified influencing factors or integrates the discussed trilateral relationships; none covers the identified mixed OPP strategies. Yet, when deciding about the position of an order penetration point within an automotive supply chain all these design options have to be taken into account.

Considering the size and complexity of a single OPP problem, analytical models as well as heuristics have been assessed as rather unsuitable to master all named challenges thoroughly. Neither dynamics, e.g. inflicted by the agility and flexibility requirements, nor complexity, e.g. inflicted by product variety proliferation but also symptomatic for global automotive supply chains, may be taken into account sufficiently. Yet, in order to allow for rapid modelling and evaluating of several OPP design variants, the application of analytical assessment bears strong arguments.

Nevertheless, for thorough assessment of OPP problems in such dynamic environment the application of simulation techniques provides valuable insight. The idea to evaluate problems by replicating the dynamic supply chain system and its behaviour is plausible. Nevertheless, considering the size and complexity of the OPP problem 
in automotive networks, a simulation based evaluation of all OPP variants cannot be accomplished; neither data wise nor within a reasonable time frame.

Therefore a methodology integrating both approaches has been developed and has already proven its efficiency in several projects (Klingebiel and Seidel, 2007; Saroemba et al., 2005; Schwede et al., 2011).

The methodology for OPP positioning is divided into three main elements:

- A process for OPP positioning;

- An analytical methodology;

- A simulation-based methodology.

The process for OPP positioning (Figure 2) is a result of an adaption of a proven supply chain design process (Klingebiel and Seidel, 2007). It is divided into the two main phases of specification of scope (shaded processes) and assessment of OPP design variants.

During the first phase, design options are developed based on a given market and product segmentation as well as anticipated demand uncertainty and supply chain responsiveness. Competitive strategy, product development strategy and supply chain

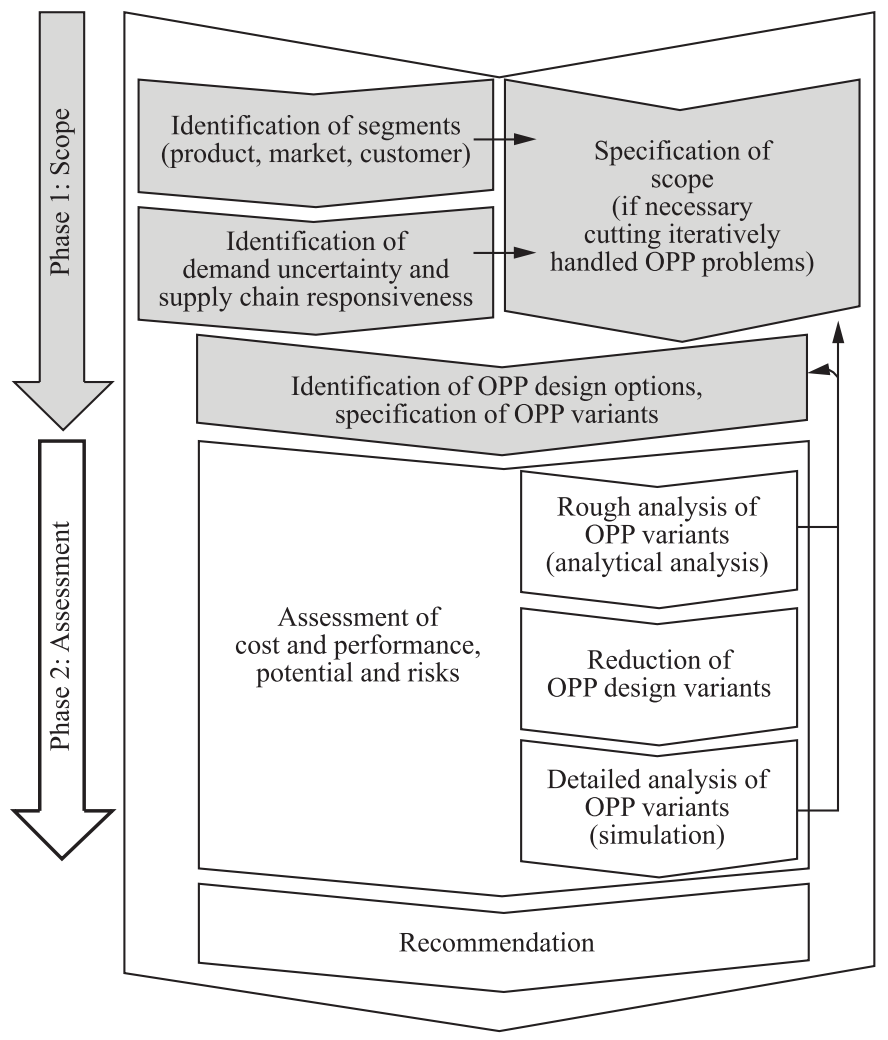

Figure 2. Procedure model for OPP positioning. 
strategy are necessarily to take into regard. Following the cycle-view (Chopra and Meindl, 2007), the positioning of several order penetration points in one supply chain may be persecuted iteratively, i.e. one by one, in following the supply chain upstream.

Subsequently, in phase 2 a first analysis reduces the possible large number of supply chain configurations drastically to feasible and economically scenarios. As a starting point for this methodology a structured framework has been developed that qualitatively and causally links factors, that affect the positioning of the OPP, thereby especially relating factors to product variety (Winkler, 2010; Lechner et al., 2011). Resulting, among the total number of drivers are as different driver as article value and weight, supplier reliability, accepted delivery time, cycle time or aspects of underlying network topology.

The developed static calculation method integrates the subset of nondynamic drivers and provides an evaluation of average lead times and several cost factors for different alternatives of OPP positions. Product variety-specific factors are integrated by a Variety-Driven ABC analysis (Lechner et al., 2011). Thus each supply chain configuration is assessed and several OPP positions can be excluded on basis of predefined acceptable lead time and cost corridors.

From the remaining set of possible supply chain configurations, scenarios for a detailed analysis are derived. In the next step these scenarios need to be assessed in detail and thoroughly by help of simulation techniques which integrates dynamic aspects and provides resulting, high granularity KPIs. Here information flow as well as material flow has to be taken into account, thus a supply chain simulation is recommended.

A suitable simulation environment is given by OTD-NET, developed by the Fraunhofer Institute for Material Flow and Logistics (Wagenitz, 2007). OTD-NET introduces a holistic approach for modeling and simulation of complex production and logistics networks and delivers in-depth insights into information and material flows, stock levels, network stability and flexibility, boundary conditions and restrictions. As OTD-NET calculates a large variety of supply chain KPI, a suitable target system is required to assess the influence of selected drivers on the OPP position. (Klingebiel et al., 2010) presents an applicable system including the detailed specification of indicators.

In order to evaluate order penetration point scenarios in global supply chains, performance and costs of current and scenario-related supply chain processes have to be assessed. Reflecting a specific supply chain strategy OPP positioning has to realize selected and variably prioritized objectives. Thus, any OPP design option has to be measured against corresponding KPIs. Our studies revealed that most performance measurement systems offer indicators that can be assigned to one of the two categories "supply chain costs" with the objective of costs reduction and the "supply chain performance" with the objective of performance increase (Pires e Sacomano Neto, 2009, Braz et al., 2011, Cirullies et al., 2011). Exemplarily the German industrial guidelines 4400 (Verein deutscher Ingenieure, 2002) as well-established and holistic framework covering the whole supply chain has been selected. The indicators presented there aggregate the objectives of high performance and low costs to a ratio of logistics efficiency. The authors expanded the two-objective indicator system by the third objective "low ecological burden". Respective objectives and KPI have been specified and integrated (Cirullies et al., 2011) (Figure 3). 


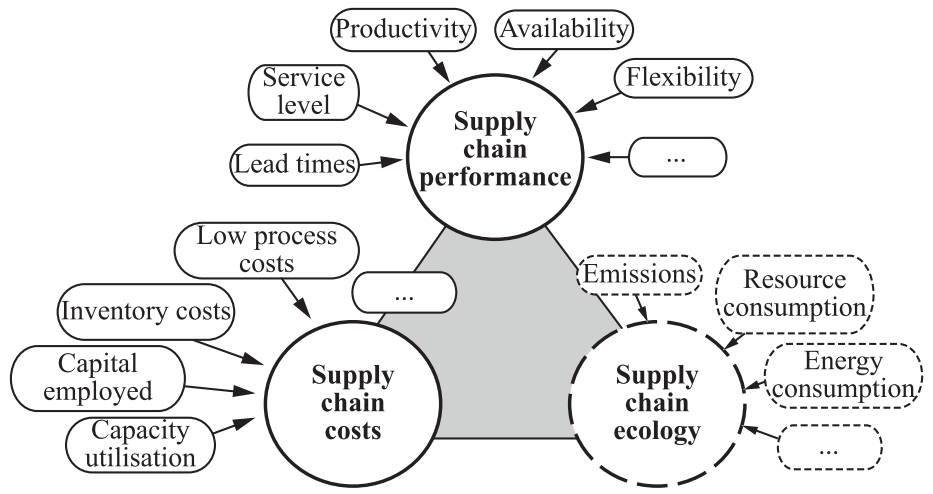

Figure 3. Targets of logistics OPP assessment.

With this preliminary work the supply chain simulation is capable of analysing dissected order penetration point problems, thus only covering a restricted area of supply chain. Nevertheless, the dynamic analysis unfolds its true potential with capturing and assessing the combination of subsequently following OPPs in combination with process concepts like ATO, LTO and postponement. Under consideration of supply chain and demand uncertainty, supply chain risks, complex planning and control processes the OTD-NET delivers time series of inventory levels, lead times, costs and more, thus even allowing to derive service level aspects like supply chain reliability depending on the supply chain configuration.

\section{Validation}

In one of the case study a distribution supply chain providing distributors with automotive wearing parts has been analysed. In focus has been a supply chain section including a plant in Germany, a nearby distribution center and European distributors, e.g. in Munich, Germany. The shipping volume comprised one article weighting $55 \mathrm{~kg}$ with a mean demand of 30 parts per month. The transportation of about $600 \mathrm{~km}$ from Wolfsburg to Munich was performed by a truck of $7.5 \mathrm{t}$ of total weight.

After analyzing demand uncertainty and supply chain responsiveness, three basic OPP scenarios have been developed: 1) OPP at the distributor, (2) OPP at the distribution center and (3) OPP at the plant. The combination with two transportation strategies resulted in a total of six OPP scenarios: a) truck leaving not more than 10 hours after call-off; b) truck leaving after 48 hours or on full charge. Due to the already limited number of OPP scenarios, all scenarios have been simulated with OTD-NET. The respective results are presented in Table 1.

The case clearly demonstrates the interconnection between economical, ecological and performance-related objectives: An OPP position at the end of the supply chain (scenarios 1a and $1 \mathrm{~b}$ ) results in an extremely short order-to-delivery time, but leads to high stock levels which relate to respective supply chain costs. Simulation reveals to what extent a shift of the OPP upwards may reduce inventory in the supply chain. However, the order-to-delivery time increases significantly.

The ecological impact is evaluated as average $\mathrm{CO}_{2}$ emission per part. As parts can be consolidated by lower transportation frequency (scenarios 1b, 2b, 3b), the number 
Table 1. Simulation results.

\begin{tabular}{|c|c|c|c|c|c|c|c|c|c|c|}
\hline & \multicolumn{2}{|c|}{ 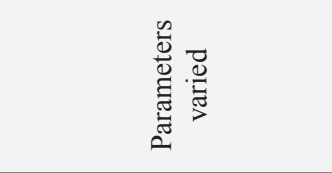 } & 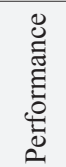 & \multicolumn{3}{|c|}{ ô } & \multicolumn{4}{|c|}{ 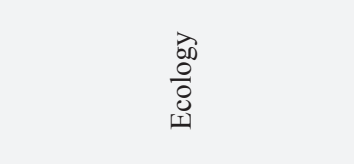 } \\
\hline 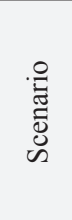 & के & 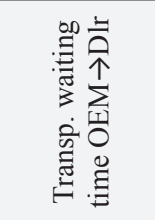 & 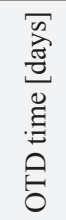 & $\begin{array}{l}\overrightarrow{0} \\
\ddot{\Xi} \\
\ddot{\Xi} \\
\overrightarrow{0} \\
\ddot{0} \\
\dot{0} \\
\dot{0}\end{array}$ & 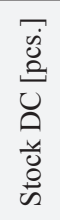 & 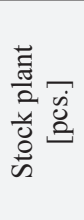 & 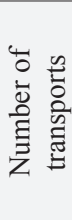 & 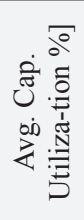 & 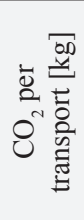 & 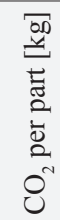 \\
\hline Scla & Distributor & $\begin{array}{l}10 \text { hours or } \\
\text { full load }\end{array}$ & 0.0 & 1354 & 157 & 974 & 265 & 0.667 & 83.81 & 2.10 \\
\hline $\mathrm{Sc} 2 \mathrm{a}$ & $\mathrm{DC}$ & $\begin{array}{l}10 \text { hours or } \\
\text { full load }\end{array}$ & 12.6 & 0 & 88 & 1737 & 222 & 0.796 & 86.92 & 1.82 \\
\hline Sc3a & Plant & $\begin{array}{l}10 \text { hours or } \\
\text { full load }\end{array}$ & 14.8 & 0 & 87 & 213 & 231 & 0.765 & 86.17 & 1.88 \\
\hline $\mathrm{Sc} 1 \mathrm{~b}$ & Distributor & $\begin{array}{l}48 \text { hours or } \\
\text { full load }\end{array}$ & 0,0 & 1351 & 157 & 974 & 210 & 0.841 & 88.01 & 1.74 \\
\hline $\mathrm{Sc} 2 \mathrm{~b}$ & $\mathrm{DC}$ & $\begin{array}{l}48 \text { hours or } \\
\text { full load }\end{array}$ & 12.8 & 0 & 88 & 1737 & 207 & 0.853 & 88.31 & 1.72 \\
\hline $\mathrm{Sc} 3 \mathrm{~b}$ & Plant & $\begin{array}{l}48 \text { hours or } \\
\text { full load }\end{array}$ & 15.3 & 0 & 87 & 213 & 231 & 0.765 & 86.17 & 1.88 \\
\hline
\end{tabular}

of transports decreases significantly by up to $20 \%$ compared to the scenarios $1 \mathrm{a}, 2 \mathrm{a}$, 3a. The improved capacity utlisation reduces the $\mathrm{CO}_{2}$ emission per part by up to $17 \%$.

This analysis demonstrates that all OPP scenarios have a significant impact on the environmental and ecological targets. The proposed methodology allows assessment of these impacts and supports the decision if cutbacks in matters of performance and/ or costs are accepted.

\section{Conclusion and Outlook}

Globalization and market saturation require a fitting competitive strategy. As a reaction, OEMs have and will enlarge their model and option range considerably. Though product diversity is handled differently in industrialized and emerging countries, the basic mechanisms are identical. But augmenting product diversity is introducing complexity and uncertainty into the supply chain thus influencing the supply chain configuration and so costs, service levels and risks.

Enterprises in a supply chain are driven by the obstacles to balance downstream flexibility with upstream stability. Nevertheless the most efficient supply chain is the one most prone to uncertainty and risks. Thus, in order to economically operate the supply chain, the positioning of order penetration points is vital to be amenable to changing market demand and to allow for accurate and risk-controlled planning of cost-efficient supply chain processes. 
Though many authors have already contributed to this problem, these approaches work with a fairly abstract conception of order penetration points. The presented methodological approach overcomes this lack of practicality without neglecting the need for quick first results. The integration of a first analytical step focussing on static drivers with a following simulation-based assessment of uncertainty and risks provides the potential for consistent and thorough assessment of global supply chain configurations in automotive industry. Thus, the proposed methodology allows assessing the impact of design options for involved upstream and downstream processes as all influencing factors can be integrated into the simulation and assessment criteria for involved upstream and downstream processes can be integrated freely. For example, the presented case study demonstrates how transport strategies influence the optimality of a certain OPP design option. Especially it was revealed that the ecological footprint of a supply chain, i.e. $\mathrm{CO}_{2}$ emissions part, depend on a chosen OPP scenario.

The combined approach of analytical and simulation-based assessment has already proven its success in other problem areas (Saroemba et al., 2005; Klingebiel et al., 2010); each methodological approach has proven valid for itself (Lechner et al., 2011; Cirullies et al., 2011). One part of the future work shall now be dedicated to prove its further synergetic combination in case studies, both in industrialized and emerging countries.

Furthermore, we notice that within supply chain research increasing attention is drawn to environmental protection on the one hand and supply chain risk management on the other hand. Both objectives will influence the configuration of supply chains widely. To integrate associated drivers as well as KPI into the presented methodological approach is one of the planned next steps.

\section{Acknowledgements}

The Authors gratefully acknowledge the Brazilian and German research agencies CAPES \& DFG (BRAGECRIM project KU 619/19-1 and Project 10/09) and MCT/CNPq (project 309455/2008-1).

\section{References}

Andries, B. and Gelders, L. (1995) Time-based manufacturing logistics. Logistics Information Management, Vol. 8, pp. 25-31. http://dx.doi. org/10.1108/09576059510102208

Barry, J. (2004) Supply chain risk in an uncertain global supply chain environment. International Journal of Physical Distribution and Logistics Management, Vol. 34, pp. 695-697. http://dx.doi.org/10.1108/09600030410567469

Bayus, B.L. and Putsis Junior, W.P. (1999) Product proliferation, An empirical analysis of product line determinants and market outcomes. Marketing Science, Vol. 18, pp. 137-153. http://dx.doi.org/10.1287/mksc.18.2.137

Bowersox, D.J. and Morash, E.A. (1989) The Integration of Marketing Flows in Channels of Distribution. European Journal of Marketing, Vol. 23, pp. 58-67. http:// dx.doi.org/10.1108/EUM0000000000546 
Bozarth, C. and Chapman, S. (1996) A contingency view of time-based competition for manufacturers. International Journal of Operations and Production Management, Vol. 16, pp. 56-67. http://dx.doi.org/10.1108/01443579610119090

Chopra, S. and Meindl, P. (2007) Supply Chain Management. Prentice Hall International.

Christopher, M. (2005) Logistics and supply chain management, creating value-adding networks. Harlow: FT Prentice Hall.

Christopher, M. and Towill, D.R. (2000) Supply chain migration from lean and functional to agile and customized. Supply Chain Management: An International Journal. Vol. 5, pp. 206-213. http://dx.doi.org/10.1108/13598540010347334

Cirullies, J.; Klingebiel, K and Scavarda, L.F. (2011) Integration of Ecological Criteria Into The Dynamic Assessment Of Order Penetration Points In Logistics Networks, in: Proceedings 25th European Conference on Modelling and Simulation ECMS 2011.

Gunasekaran, A. and Ngai, E.W.T. (2005) Build-to-order supply chain management, a literature review and framework for development. Journal of Operations Management, vol. 23, pp. 423-451. http://dx.doi.org/10.1016/j.jom.2004.10.005

van Hoek, R. (2001) The rediscovery of postponement a literature review and directions for research. Journal of Operations Management, Vol. 19, pp. 61-184. http://dx.doi.org/10.1016/S0272-6963(00)00057-7

Holweg, M. and Pil, F.K. (2004) The second century, reconnecting customer and value chain through build-to-order. Cambridge: MIT Press.

Klingebiel, K. and Seidel, T. (2007) Transforming the Automotive Industry by Rapid Supply Chain Design, New technologies for the intelligent design and operation of manufacturing networks - Results and perspectives from the European AITPL Project cluster. Stuttgart: IRB Verlag, pp. 53-70.

Klingebiel, K.; Gavrylenko, Y. and Wagenitz, A. (2010) Adoption Of Simulation Techniques For Mastering Logistic Complexity Of Major Construction And Engineering Projects, in: Proceedings 24th European Conference on Modelling and Simulation ECMS 2010, pp. 160-168.

Klingebiel, K. (2009) Entwurf eines Referenzmodells für Built-to-orderKonzepte in Logistiknetzwerken der Automobilindustrie. Dortmund: University Dissertation-Dortmund, Verlag Praxiswissen.

Klingebiel, K.; Scavarda, L.F.; Winkler, H. and Wagenitz, A. (2011) Logistikkompetenz in Brasilien. Transfer erprobter logistischer Methoden in einen Entwicklungsmarkt. Industrie Management, Vol. 2, pp. 33-37

Kotler, P.; Wong, V.; Saunders, J. and Armstrong, G. (2005) Principles of marketing. Harlow: FT Prentice Hall

Kuhn,A.; Wagenitz,A. and Klingebiel, K. (2010) Praxis Materialflusssimulation, Antworten zu oft zu spät, Jahrbuch der Logistik. Korschenbroich: free beratung Gesellschaft für Kommunikation im Marketing mbH. 
Lambert, D. and Cooper, M. (2000) Issues in Supply chain management. Industrial Marketing Management, Vol. 29, pp. 65-83. http://dx.doi.org/10.1016/ S0019-8501(99)00113-3

Lancaster, K. (1990) The economics of product variety, A survey. Marketing Science, Vol. 9, pp. 189-206. http://dx.doi.org/10.1287/mksc.9.3.189

Lechner, A.; Klingebiel, K. and Wagenitz, A. (2011) Evaluation of product variant-driven complexity costs and performance impacts in the automotive logistics with Variety-driven Activity-based Costing, in: Proceedings of the International Multiconference of Engineers and Computer Scientists.

Midler, C. (2005) Innovation Based Competition in Auto Industry, New Challenges for Design Organization and Co-Innovation Processes. Tokyo: IMVPMMRC, Hosei University. Working Paper.

Olhager, J. (2003) Strategic positioning of order penetration point. International Journal of Production Economics, Vol. 85, pp. 319-329. http://dx.doi. org/10.1016/S0925-5273(03)00119-1

Pine, B.J. (1993) Mass customization, The new frontier in business competition. Boston: Havard Business School Press.

Pires, S.R.I. and Diaz, L.E.C. (2007) Gestión de la Cadena de Suministros. McGrawHill, pp. 258-280.

Pires, S. and Sacomano Neto, M. (2008) New configurations in supply chains: the case of a condominium in Brazil's automotive industry. Supply Chain Management: an international journal, Vol. 13, No. 4, pp. 328-334. http://dx.doi. org/10.1108/13598540810882215

Randall, T. and Ulrich, K. (2001) Product variety, supply chain structure, and firm performance, analysis of the U.S. bicycle industry. Management Science, Vol. 47, pp. 1588-1604. http://dx.doi.org/10.1287/mnsc.47.12.1588.10237

Sanchez, A.M. and Perez, M.P. (2005) Supply chain flexibility and firm performance: A conceptual model and empirical study in the automotive industry. International Journal of Operations \& Production Management, Vol. 25, pp. 681-700. http://dx.doi.org/10.1108/01443570510605090

Saroemba, R.; Weller, R.; Klingebiel, K and Motta, M. ( 2005) Simulationsgestützte Planung eines globalen Zuliefer- und Produktionsnetzwerks, Jahresbericht Fraunhofer IML. Fraunhofer-Institut für Materialfluss und Logistik, pp. 52-53.

Scavarda, L.F.; Reichhart, A.; Hamacher, S and Holweg, M. (2010) Managing product variety in emerging markets. International Journal of Operations \& Production Management, Vol. 30, pp. 205-224. http://dx.doi.org/10.1108/01443571011018716

Scavarda, L.F.; Schaffer, J.; Scavarda, A. J.; Reis A.C. and Schleich, H. (2009) Product variety: an auto industry analysis and a benchmarking study. Benchmarking: An International Journal, Vol. 16, pp. 387-400. 
Schaffer, J. (2010) Entwicklung und Optimierung eines treiberbasierten Modells zur Bewertung varianteninduzierter Komplexitätskosten in industriellen Produktionsprozessen. Sierke Verlag.

Schwede, C.; Klingebiel, K.; Pauli T. and Wagenitz, A. (2011) Simulationsgestützte Optimierung für die distributionsorientierte Auftragsreihenfolgeplanung in der Automobilindustrie, Simulation und Optimierung in Produktion und Logistik - Praxisorientierter Leitfaden mit Fallbeispielen. Berlin Heidelberg: Springer-Verlag Berlin Heidelberg, pp. 151-170.

Sharman, G. (1984) The rediscovery of logistics. Harvard Business Review, Vol. 62, pp. 71-80.

Da Silveira, G. (1998) A framework for the management of product variety. International Journal of Operations and Production Management, Vol. 18, pp. 271-285. http://dx.doi.org/10.1108/01443579810196471

Slack, N. (1983) Flexibility as manufacturing objective. International Journal of Operations and Production Management, Vol. 7, pp. 35-45. http://dx.doi. org/10.1108/eb054798

Shile, Y.-R. (2009) Development of two-level decision tree-based realtime scheduling system under product mix variety environment. Robotics and Computer-Integrated Manufacturing, Vol. 25, pp. 709-720. http://dx.doi.org/10.1016/j. rcim.2008.06.002

Simchi-Levi, D.; Kaminsky, P. and Simchi-Levi, E. (2007) Designing and Managing the Supply Chain: Concepts. McGraw-Hill: Strategies and Case Studies.

Stäblein, T.; Holweg, M. and Miemczyk, J. (2011) Theoretical versus actual product variety, how much customization do customers really demand?. International Journal of Operations \& Production Management., Vol. 31, pp. 350-370. http://dx.doi. org/10.1108/01443571111111955

Syam, N.; Ruan, R. and Hess J. (2005) Customized products, a competitive analysis. Marketing Science, Vol. 24, pp. 569-584. http://dx.doi.org/10.1287/ mksc. 1050.0128

Tachizawa, E. and Gimenez C. (2007) The drivers and sources of supply flexibility: An exploratory study. International Journal of Operations and Production Management, Vol. 27, pp. 115-1136. http://dx.doi.org/10.1108/01443570710820657

Tang, O. and Nurmaya, M.S. (2010) Identifying risk issues and research advancements in supply chain risk management. International Journal of Production Economics (in press).

Tang, E.P.Y. and Yam, R.C.M. (1996) Product variety strategy, an environmental perspective. Integrated Manufacturing Systems, Vol. 7, pp. 24-29. http:// dx.doi.org/10.1108/09576069610151158

Toth, M.; Seidel, T. and Klingebiel, K. (2008) Moving towards BTO - An Engine Case Study. Build to Order, The Road to the 5 Day Car, Springer London Ltd, pp. 297-310. 
Thun, J.H. and Hoenig, D. (2011) An empirical analysis of supply chain risk management in the German automotive industry. International Journal of Production Economics, Vol. 131, pp. 242-249. http://dx.doi.org/10.1016/j.ijpe.2009.10.010

Upton, D. (1994) The management of manufacturing flexibility. California Management Review, Vol. 36, pp. 72-89.

Vaagen, H. and Wallace, S.W. (2008) Product variety arising from hedging in the fashion supply chains. International Journal Production Economics, Vol. 114, pp. 431-455. http://dx.doi.org/10.1016/j.jpe.2007.11.013

Wagenitz, A. (2007) Modellierungsmethode zur Auftragsabwicklung in der Automobilindustrie, Verlag Praxiswissen, Dortmund.

Winkler, H. (2010) Beitrag zur Positionierung von Kundenentkopplungspunkten in Produktionsnetzwerken. Dortmund.

$\mathrm{Wu}, \mathrm{Y}$. (2006) Robust optimization applied to uncertain production loading problems with import quota limits under the global supply chain management environment. International Journal of Production Research, Vol. 44, pp. 849-882. http:// dx.doi.org/10.1080/00207540500285040

Wu, Y.; Frizelle, G. and Estathiou, J. (2007) A study on the cost of operational complexity in customer-supplier systems. International Journal Production Economics, Vol. 106, pp. 217-229. http://dx.doi.org/10.1016/j.ijpe.2006.06.004

Yang, B.; Burns, N. and Backhouse, C. (2004) Management of uncertainty through postponement. International Journal of Production Research, Vol. 42, pp. 1049-1064. http://dx.doi.org/10.1080/00207540310001631601

\section{Biography}

Katja Klingebiel is head of the Research Center for Logistics Assistance Systems at the Fraunhofer Institute for Material Flow and Logistics in Dortmund, Germany. She studied applied mathematics and obtained her Doctoral Degree (Dr.-Ing.) at the Faculty of Mechanical Engineering in Dortmund. She worked several years in automotive consulting as well as for the Fraunhofer Institute for Material Flow and Logistics. Her areas of expertise include supply chain management, order management and business process reengineering.

Contact: katja.klingebiel@iml.fraunhofer.de

Bernd Hellingrath is Full Professor for Information Systems and Supply Chain Management at the University of Münster. From 2006 to 2008 he was Professor for Information Systems, esp. Planning and Modeling of Production and Logistics Networks at the University of Paderborn. From 1988 to 2008 he joined the Fraunhofer Institute of Material Flow and Logistics as head of different departments and researcher. His Doctoral Degree (Dr.-Ing.) was obtained at the Faculty of Mechanical Engineering at University of Dortmund.

Contact: bernd.hellingrath@wi.uni-muenster.de 
Silvio R. I. Pires is graduated and has a master and doctoral degree in Production Engineering and more than twenty five years of professional experience as industrial manager, consulting and professor of operations and supply chain management in Brazil, Switzerland, Spain, and France. Currently he is a full professor at the Methodist University of Piracicaba (UNIMEP) in Brazil, and an inviter professor in France and Spain. Alongside he has been working for large companies in Brazil and Europe.

Contact: sripires@unimep.br

Luiz Felipe Scavarda is Professor at the Industrial Engineering Department of PUC-Rio. His Graduate, Master, and Doctoral degrees in Industrial Engineering were obtained at PUC-Rio. His areas of expertise are in the field of supply chain management, having: conducted research and industrial projects in different countries. During 2000/2002 he joined as visiting researcher the German Fraunhofer Institute for Manufacturing Engineering and Automation and in 2009 he was a post-doctoral fellow at the Vienna University of Technology.

Contact: lf.scavarda@puc-rio.br

\section{Article Info:}

Received: September, 2011

Accepted: December, 2011 